\title{
Multiwalled carbon nanotubes decorated with bismuth (III) oxide for electrochemical detection of an antipyretic and analgesic drug paracetamol in biological samples
}

\author{
Arthur T. Chipeture, Daniel Apath, Mambo Moyo* ${ }^{*}$ and Munyaradzi Shumba
}

\begin{abstract}
Background: In the present work, an electrochemical sensor for detection of paracetamol was fabricated by modifying a glassy carbon electrode (GCE) using multiwalled carbon nanotube (MWCNT) decorated with bismuth oxide $\left(\mathrm{Bi}_{2} \mathrm{O}_{3}\right)$ based on using the drop dry technique.

Methods: The prepared composite electrode was characterized by scanning electron microscopy-energy dispersive X-ray spectroscopy (SEM-EDS), Fourier transform infrared spectroscopy (FT-IR), and cyclic voltammetry (CV). Electrochemical techniques such as cyclic voltammetry, chronoamperometry, and square wave voltammetry (SWV) were used to study the behavior of paracetamol.

Results: The modification process improved the redox kinetics of paracetamol as shown by increased peak currents. The peak current varied linearly with increment of paracetamol concentration in the range of 0.02 to $28 \mu \mathrm{M}$ with a sensitivity of $1.133 \mu \mathrm{A} \mu \mathrm{M}^{-1}$. A detection limit of $0.0052 \mu \mathrm{M}$ was obtained.

Conclusion: The proposed method was successfully applied to determination of paracetamol in biological samples with recoveries in the range 94.3-98.7\%.
\end{abstract}

Keywords: Paracetamol, Bismuth (III) oxide, Multiwalled carbon nanotube, Voltammetry

\section{Introduction}

Paracetamol (Scheme 1) is mainly used as an antipyretic and analgesic drug in most countries for relief of mild to moderate pain associated with headache, arthritis, backache, toothaches, and postoperative pain (Jia et al. 2007; Kachoosangi et al. 2008; Devaraj et al. 2013). No harmful side effects caused by paracetamol have been reported when taken in normal therapeutic doses. Nevertheless, abnormal level of paracetamol has been reported to cause formation of some liver and nephrotoxic metabolites (Rowden et al. 2006).

Furthermore, increased problems such as rhinoconjunctivitis, asthma, and eczema have been reported in children younger than 1 year after consumption of paracetamol (Sullivan and Farrar 2011). For quality control

\footnotetext{
* Correspondence: moyom@staff.msu.ac.zw

Sensor Lab Research Group, Department of Chemical Technology, Midlands State University, Private Bag 9055, Senga, Gweru, Zimbabwe
}

purposes and its widespread use on a daily basis in different countries, the monitoring of trace amounts of paracetamol in fluids is of great interest since little is known about potential chronic health effects associated with long-term ingestion.

Current analytical techniques that have been reported for quantification of paracetamol in different environmental matrices include capillary electrophoresis (Sultan et al. 2013), high-performance liquid chromatography (Abdelaleem and Abdelwahab 2013), and liquid chromatographymass spectrometry (Lou et al. 2010). The aforementioned methods are sensitive and reliable. Conversely, they are expensive instrumental techniques that require substantial times for sample pretreatment and require qualified and experienced technicians making them unsuitable for routine analysis (Gowda et al. 2015). In recent years, electrochemical methods have proven to be good since they offer the opportunities like portability, sensitivity, less 


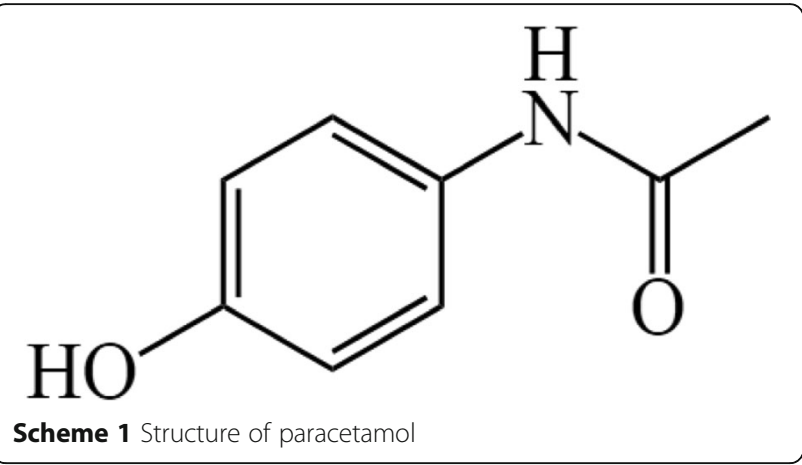

expenses, reproducibility, and rapid methodologies (Gupta et al. 2006; Moyo et al. 2015; Bouabi et al. 2016).

In the recent decade, various chemically modified electrodes have been used to determine paracetamol based on its molecular structure which is electrochemically active. The modification has also been applied in an attempt to reduce poor voltammetric responses caused by sluggish electrode kinetics and electrode fouling encountered at bare electrode which decrease sensitivity and reproducibility (Bouabi et al. 2016). Modifiers such as multiwalled carbon nanotube-cetyltrimethyl ammonium (Gowda et al. 2015), chitosan (Bouabi et al. 2016), graphene (Kang et al. 2010), carbon nano-tube composite film ( $\mathrm{Li}$ et al. 2006), magnesium diboride microparticles (Zidan et al. 2011a, 2011b), nafion/ $/ \mathrm{TiO}_{2}$-graphene (Fan et al. 2011), bismuth oxide nanoparticles (Zidan et al. 2011a, 2011b), nickel and nickel-copper alloy (Feizbakhsh et al. 2012), graphene oxide (Zidan et al. 2014), multiwalled carbon nanotubes and dopamine nanospheres functionalized with gold nanoparticles (Liu et al. 2014), nickel oxide nanoparticles and carbon black (Deroco et al. 2014), cuprous oxide nanoparticles-graphene (Yang et al. 2015), graphene (Fernandez et al. 2015), single-walled carbon nanotube/ nickel nanocomposite(Ngai et al. 2015), cadmium selenide microspheres (Yin et al. 2012), and poly(glycine) (Kuskur et al. 2015) have offered great success for the decrease in overpotential and increase of sensitivity during oxidation of paracetamol. Even though the aforementioned modifiers have proved to be effective, a search for new combinations should still continue so that better sensitivity, selectivity, and good stability are achieved during electrochemical detection.

Since their discovery, carbon nanotubes especially multi-walled carbon nanotubes (MWCNTs) have been used in sensors due to their superior properties such as a large electrochemically accessible area, high electrical conductivity, high reactivity, and selectivity, as well as great chemical stability, electrocatalytic properties, capability to reduce the overpotentials, and the ability to improve significantly both the anodic and cathodic peak currents in redox systems (Gowda et al. 2015; Ovsienko et al. 2007). Bismuth oxide $\left(\mathrm{Bi}_{2} \mathrm{O}_{3}\right)$ is a well-known transition metal oxide with varied interesting characteristics such as its thermal, energy band gap, photoconductivity, large surface area, and good electrochemical stability (Li and Yan 2009; Periasamy et al. 2011; Chen et al. 2009). In the present work, a cheap composite prepared from MWCNT and $\mathrm{Bi}_{2} \mathrm{O}_{3}$ was used with the intent to exploit their synergistic effects. Various graphitic materials such as graphene oxide, single-walled carbon nanotubes, and graphene quantum dots have shown enhanced current densities with high potential of increasing detection signals. Metal centers on the other hand act as catalytic sites as shown before (Mafuwe et al. 2019). Graphitic materials provide abundant binding sites for the metal center and improve conductivity $(\mathrm{Xu}$ et al. 2015) hence the need to combine the two. As far as we could ascertain, the use of a $\mathrm{Bi}_{2} \mathrm{O}_{3} / \mathrm{MWCNT}$ composite deposited on the glassy carbon electrode for the determination of paracetamol has not been reported. The electrochemical oxidation of paracetamol using modified electrodes was investigated by cyclic voltammetry $(\mathrm{CV})$, chronoamperometry, and square wave voltammetry (SWV). The proposed method was applied to urine samples.

\section{Materials and experimental methods Materials}

All reagents were of analytical grade and were used without further purification. Paracetamol, $\mathrm{N}, \mathrm{N}$-dimethylformamide (DMF), $\mathrm{Bi}_{2} \mathrm{O}_{3}$ nanopowder (particle size of $21 \mathrm{~nm}$, MWCNT-purity of $95 \%$, diameter 20-40 nm, and length $\sim 5-15 \mu \mathrm{m})$, potassium ferricyanide $\left(\mathrm{K}_{3} \mathrm{Fe}(\mathrm{CN})_{6}\right)$, and potassium ferrocyanide $\left(\mathrm{K}_{4} \mathrm{Fe}(\mathrm{CN})_{6}\right)$ were purchased from Sigma-Aldrich (South Africa). Phosphate buffers solutions (PBS) at different $\mathrm{pH}$ values were prepared by mixing standard stock solutions of $0.10 \mathrm{M} \mathrm{Na}_{2} \mathrm{HPO}_{4}$ and $0.10 \mathrm{M}$ $\mathrm{NaH}_{2} \mathrm{PO}_{4}$ and adjusting the $\mathrm{pH}$ with $0.1 \mathrm{M}$ hydrochloric acid or sodium hydroxide. A stock solution of paracetamol $\left(5.0 \times 10^{-3} \mathrm{M}\right)$ was dissolved in $0.1 \mathrm{~mol} \mathrm{~L}^{-1}$ PBS. All solutions were prepared using doubly distilled water. All glassware was cleaned in a bath of freshly prepared aqua regia solution and thoroughly rinsed with distilled water thereafter.

\section{Fabrication of the sensor}

Prior to modification, the glassy carbon electrode (GCE) was sequentially polished to a mirror finish using a BASi polishing kit containing 1.0, 0.3, and $0.05 \mu \mathrm{m}$ diamond slurry, and then rinsed thoroughly in doubly distilled water before being ultrasonically rinsed in ethanol and doubly distilled water for $10 \mathrm{~min}$ to remove any adsorbed species on the electrode surface. The cleaned GCE was dried in a stream of nitrogen. The $\mathrm{Bi}_{2} \mathrm{O}_{3} /$ MWCNT composite was prepared by dispersing $\mathrm{Bi}_{2} \mathrm{O}_{3}$ 
to MWCNT $(1: 3 w / w)$ with the aid of ultrasonic agitation for $1 \mathrm{~h}$ in $1 \mathrm{~mL}$ of DMF to give $1 \mathrm{mg} \mathrm{mL}^{-1}$ dispersion. Five microliters of aliquot of the nanocomposite was cast onto the GCE surface and then dried at room temperature in an inverted beaker so that a uniform layer was formed. The resultant electrode was hereafter denoted as $\mathrm{Bi}_{2} \mathrm{O}_{3} / \mathrm{MWCNT} / \mathrm{GCE}$ and stored at room temperature when not in use. By the similar way, the $\mathrm{Bi}_{2} \mathrm{O}_{3} / \mathrm{GCE}$ and MWCNT/GCE were also prepared.

\section{Instruments and analytical procedure measurements}

FT-IR (Thermo Scientific Nicolet 6700, USA) was used to investigate the different interactions between $\mathrm{B}_{2} \mathrm{O}_{3}$ and MWCNT. To study surface morphology and presence of different elements in composite, SEM image was obtained using a TESCAN Vega TS 5136LM Electron microscope. An Auto-lab potentiostat/galvanostat (PGSTAT 302F, Eco Chemie, the Netherlands) equipped with NOVA 1.10 software was used to study electrochemical measurements. A conventional three-electrode cell consisting of a modified GCE as working electrode, an $\mathrm{Ag} / \mathrm{AgCl}$ reference electrode, and a platinum wire auxiliary electrode were used. A standard aliquot of paracetamol was added into the electrochemical cell containing $10 \mathrm{~mL}$ of $0.1 \mathrm{M}$ PBS (pH 4) which was employed as the supporting electrolyte. The solution was kept in anaerobic conditions by purging it with high-purity nitrogen for at least 15 min before and continuously during the experiments. The square wave voltammetry was used to investigate the paracetamol concentration in various solutions. Parameters were recorded in the range from 100 to $580 \mathrm{mV}$, for which the step potential of $10 \mathrm{mV}$, frequency $10 \mathrm{~Hz}$, and modulation amplitude $20 \mathrm{mV}$ were used. The parameter settings in electrochemical impedance spectroscopy (EIS) were as follows: measuring potential $0.176 \mathrm{~V}$, high frequency $10,000 \mathrm{~Hz}$, low frequency $0.01 \mathrm{~Hz}$, and amplitude $50 \mathrm{mV}$. The determination of paracetamol in spiked human urines was tested under optimized conditions so that evaluation of the method could be ascertained. All the electrochemical measurements were conducted at room temperature and performed in triplicate. The $\mathrm{pH}$ measurements were carried out with a Crison 2001 micro pH-meter (Spain).

\section{Urine samples}

Fresh urine samples were obtained from voluntary individuals. It should be noted that all experiments were performed in compliance with relevant laws and institutional guidelines. All experiments were approved and conducted in the sensor lab as guided by the Chemical Technology Department Ethics board members (P and RP 2018), Midlands State University. All participants were provided with written informed consent. $0.4 \mathrm{~mL}$ of sample was
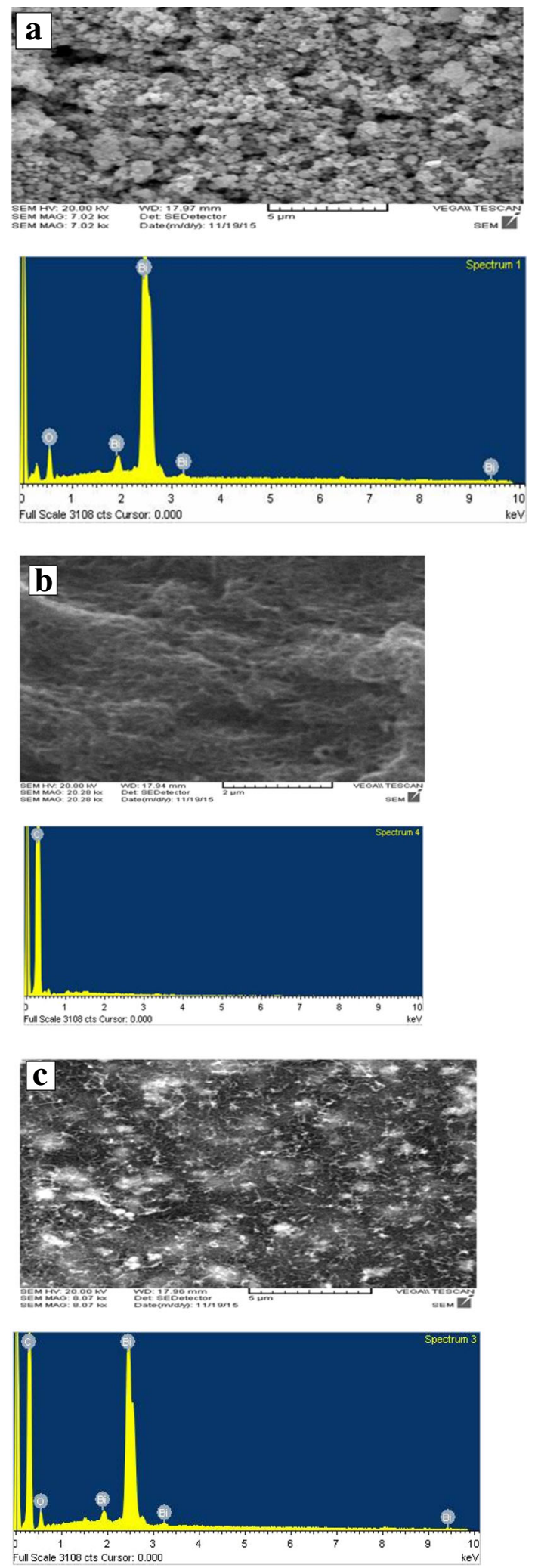

Fig. 1 SEM-EDS images of a $\mathrm{Bi}_{2} \mathrm{O}_{3}$ nanoparticles, b MWCNTs, and c $\mathrm{Bi}_{2} \mathrm{O}_{3} /$ MWCNT composite 
diluted to $10 \mathrm{~mL}$ with $0.1 \mathrm{M}$ phosphate buffer ( $\mathrm{pH} 4.0$ ) without pre-treatment step. The standard addition method was used for determination of paracetamol in urine samples after spiking aliquots of paracetamol.

\section{Results and discussion}

Surface morphological characterization studies using SEM and FT-IR

The surface morphology and elemental composition of various components used to modify the glassy carbon electrode was investigated using SEM-EDS. Figure 1a shows the SEM image of $\mathrm{Bi}_{2} \mathrm{O}_{3}$ nanoparticles. The $\mathrm{Bi}_{2} \mathrm{O}_{3}$ nanoparticles appear as flakes, spherical nanoparticles with bright spots. Interestingly, the EDS spectra exhibit well-defined peaks for $\mathrm{Bi}$ and $\mathrm{O}$ elements. Figure $1 \mathrm{~b}$ shows the SEM image of MWCNTs, with several coiled MWCNT bundles. The EDS spectrum of MWCNT shows an intense peak for the element carbon. On the other hand, the SEM image (Fig. 1c) of $\mathrm{Bi}_{2} \mathrm{O}_{3} / \mathrm{MWCNT}$ is shown with bright $\mathrm{Bi}_{2} \mathrm{O}_{3}$ nanoparticle-coated MWCNTs. Furthermore, the EDS spectrum of $\mathrm{Bi}_{2} \mathrm{O}_{3} / \mathrm{MWCNT}$ nanocomposite exhibits both $\mathrm{Bi}$ and carbon peaks, indicating the presence of $\mathrm{Bi}_{2} \mathrm{O}_{3}$ and MWCNT in the prepared nanocomposite.

Figure 2 shows the FT-IR spectra of the $\mathrm{Bi}_{2} \mathrm{O}_{3}$ nanoparticles (a), MWCNTs (b), and $\mathrm{Bi}_{2} \mathrm{O}_{3} / \mathrm{MWCNT}$ composite (c). Several well-defined peaks at 521, 613, 1400, 1636, and $3443 \mathrm{~cm}^{-1}$ are present on the $\mathrm{Bi}_{2} \mathrm{O}_{3}$ FT-IR spectrum. The sharp peaks at 559 and $613 \mathrm{~cm}^{-1}$ are related with metaloxygen (Eda et al. 2012) (Bi-O) bond. The appearance of a very short band at $1627 \mathrm{~cm}^{-1}$ might be due to the bending vibration of absorbed water and surface hydroxyl, while the broad peak $3439 \mathrm{~cm}^{-1}$ is due to the $\mathrm{O}-\mathrm{H}$ stretching mode. In Fig. 2 (b), the peak appearing at $1623 \mathrm{~cm}^{-1}$ is due to $\mathrm{C}-$ $\mathrm{C}$ stretching frequencies. After making the $\mathrm{Bi}_{2} \mathrm{O}_{3} / \mathrm{MWCNT}$ nanocomposite, the shoulder peaks appearing at 525 and $631 \mathrm{~cm}^{-1}$ increased in intensity. The obvious changes observed show that some interaction occurred.

\section{Electrochemical characterization}

The electrochemical properties of bare GCE (curve a), $\mathrm{Bi}_{2} \mathrm{O}_{3} / \mathrm{GCE}$ (curve b), MWCNT/GCE (curve c), and $\mathrm{Bi}_{2} \mathrm{O}_{3} /$ MWCNT/GCE (curve d) were characterized by CV in $10 \mathrm{mM} \mathrm{K}_{3}\left[\mathrm{Fe}(\mathrm{CN})_{6}\right]$ solution containing $0.1 \mathrm{M} \mathrm{KCl}$ at $100 \mathrm{mV} \mathrm{s}^{-1}$ (Fig. 3). It can be seen in Fig. 3 (curve a-d) that a pair of peaks corresponding to the redox reaction of ferricyanide was observed. $\mathrm{Bi}_{2} \mathrm{O}_{3} / G C E$ exhibited a negative shift in anodic peak potential although the anodic peak current of the $\left[\mathrm{Fe}(\mathrm{CN})_{6}\right]^{3-/ 4-}\left(I_{\mathrm{pa}} 41.2 \mu \mathrm{A}\right)$ was slightly less compared with the bare GCE $\left(I_{\mathrm{pa}} 42.7 \mu \mathrm{A}\right)$. Compared with $\mathrm{Bi}_{2} \mathrm{O}_{3} / \mathrm{GCE}$, the anodic peak current of $\left[\mathrm{Fe}(\mathrm{CN})_{6}\right]^{3-/ 4-}\left(I_{\mathrm{pa}} 98 \mu \mathrm{A}\right)$ on MWCNT/GCE further increased. However, the $\mathrm{Bi}_{2} \mathrm{O}_{3} / \mathrm{MWCNT} / \mathrm{GCE}$ significantly enhanced the redox peak currents, giving the highest anodic peak current $\left[\mathrm{Fe}(\mathrm{CN})_{6}\right]^{3-/ 4-}\left(I_{\mathrm{pa}} 148 \mu \mathrm{A}\right)$ compared to other electrodes. The highest electrocatalytic activity was probably attributed to $\mathrm{Bi}_{2} \mathrm{O}_{3}$ and MWCNT in the composite providing an increase in effective surface area on the GCE. Furthermore, the peak-to-peak potential separation between the cathodic and anodic peaks of the $\mathrm{Bi}_{2} \mathrm{O}_{3} / \mathrm{MWCNT} / \mathrm{GCE}$ is smaller evidence of an efficient electron transfer process (Table 1) as compared to the bare GCE, $\mathrm{Bi}_{2} \mathrm{O}_{3}$, and MWCNT/GCE. The obtained

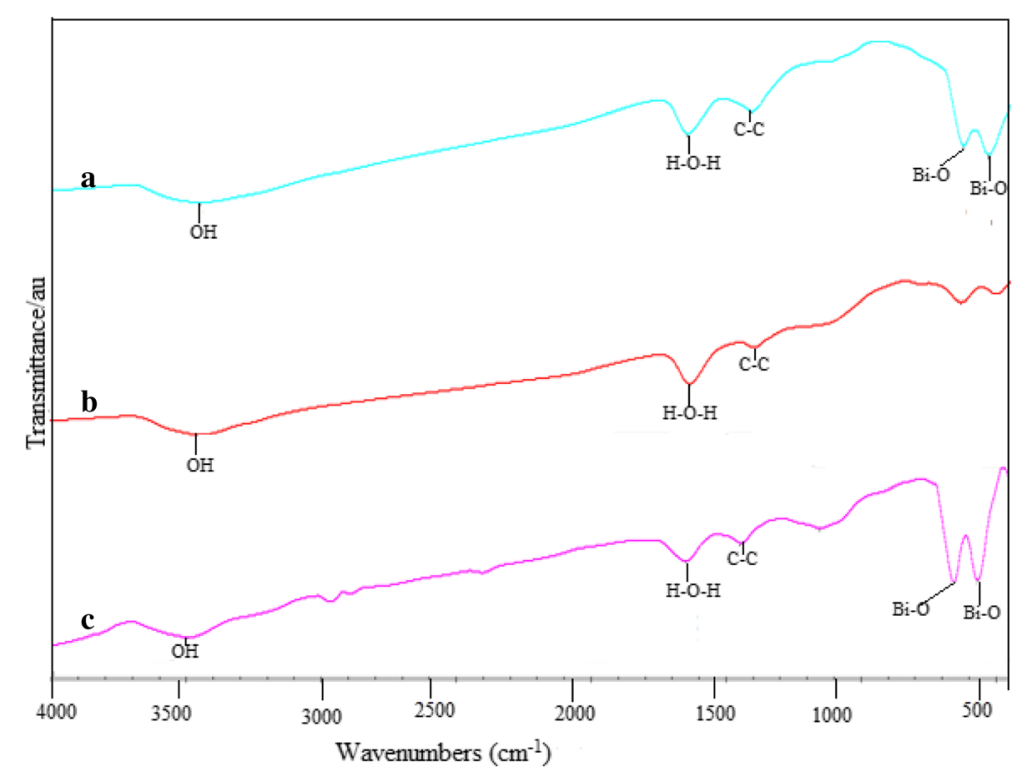

Fig. 2 FT-IR spectra of (a) $\mathrm{Bi}_{2} \mathrm{O}_{3}$ nanoparticles, (b) MWCNTs, and (c) $\mathrm{Bi}_{2} \mathrm{O}_{3} /$ MWCNT composite 


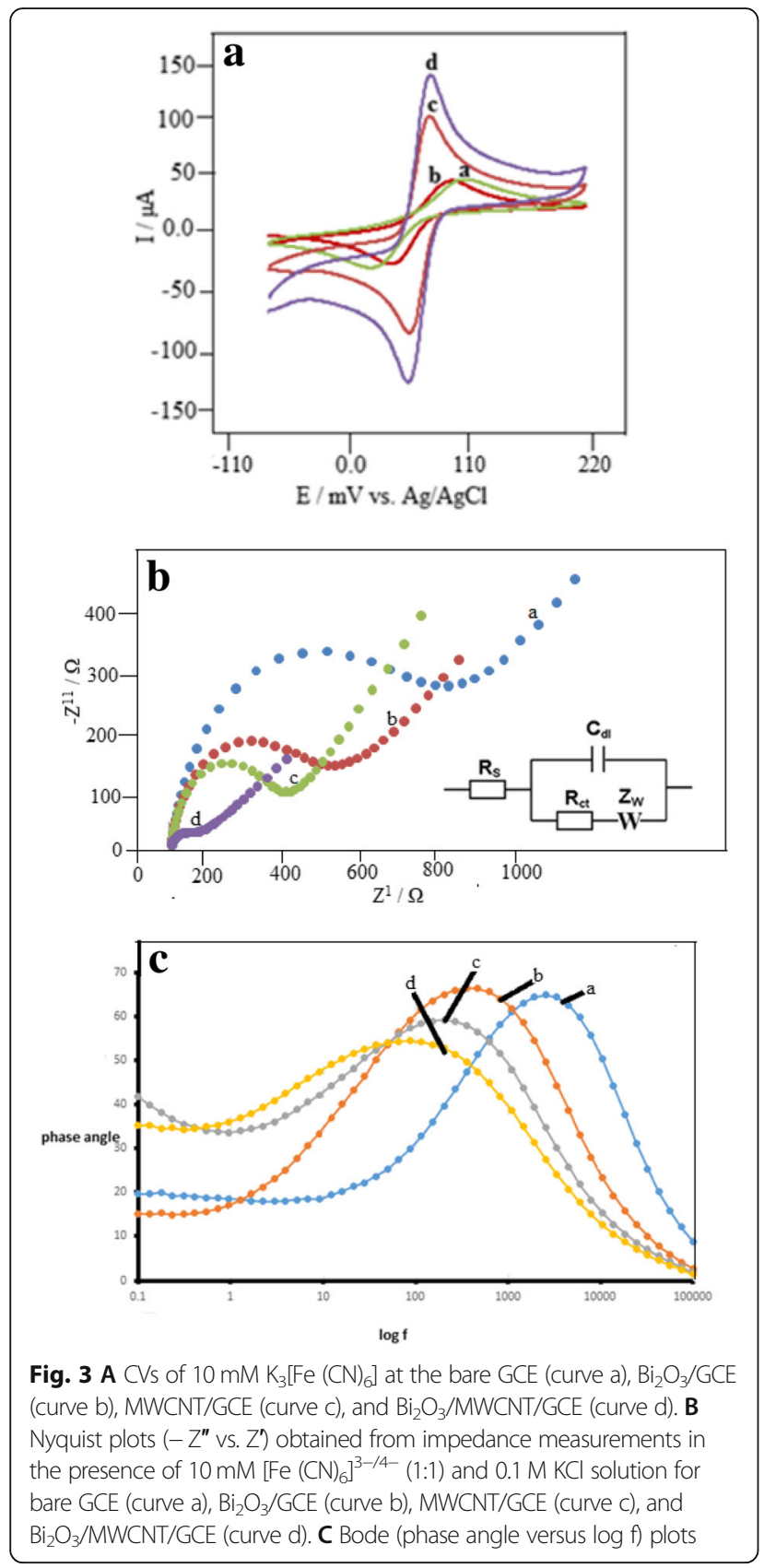

Table 1 Parameters for modified electrodes

\begin{tabular}{llll}
\hline Electrode & $\mathrm{R}_{\mathrm{c}} / \Omega$ & $i_{\mathrm{pa}} / \mu \mathrm{A}$ & $\Delta \mathrm{E}_{\mathrm{p}} / \mathrm{mV}$ \\
\hline $\mathrm{GCE}$ & 980 & 20 & 95 \\
$\mathrm{Bi}_{2} \mathrm{O}_{3} / \mathrm{GCE}$ & 600 & 21 & 86 \\
MWCNT/GCE & 410 & 98 & 67 \\
$\mathrm{Bi}_{2} \mathrm{O}_{3} / \mathrm{MWCNT} / \mathrm{GCE}$ & 50 & 146 & 65 \\
\hline
\end{tabular}

results suggested that there was a successful modification of the GCE.

The modified electrodes were further characterized by electrochemical impedance spectroscopy. Figure 3B shows Nyquist diagrams for $10 \mathrm{mM}\left[\mathrm{Fe}(\mathrm{CN})_{6}\right]^{3-/ 4-}$ in $0.1 \mathrm{M} \mathrm{KCl}$ at different electrodes. In Fig. 3B, the GCE (curve a) displays a large semi-circle at higher frequencies with a large diameter (Table 1), namely the electron transfer resistance. Curve $b$ is the Nyquist diagram of $\mathrm{Bi}_{2} \mathrm{O}_{3} / \mathrm{GCE}$ with $R_{\text {et }}=400 \Omega$. MWCNT/ GCE (curve c) showed a reduced $R_{\text {et }}$ value of $200 \Omega$ while $\mathrm{Bi}_{2} \mathrm{O}_{3} / \mathrm{MWCNT/GCE}$ (curve d) showed a further reduced $R_{\text {et }}$ value indicating good charge transfer ability in agreement with $\mathrm{CV}$ values. It can be noted that both MWCNT/GCE and $\mathrm{Bi}_{2} \mathrm{O}_{3} / \mathrm{GCE}$ enhance charge transfer as compared to the bare $\mathrm{GCE}$ and $\mathrm{Bi}_{2} \mathrm{O}_{3}$ / MWCNT/GCE further displays synergism of the modifiers under investigation. The significant improvement in electron transfer in $\mathrm{Bi}_{2} \mathrm{O}_{3} / \mathrm{MWCNT} / \mathrm{GCE}$ is a manifestation of increased electron exchange sites offered by the bismuth metallic centers with the pi electron system of the MWCNT enhancing ease of electron flow. The information from the Bode plots (Fig. 3C) further supports that modified surfaces have different behaviors since their phase angles shifted to different frequencies.

\section{Electrochemical paracetamol sensor}

The electrochemical behavior of paracetamol on GCE, $\mathrm{B}_{2} \mathrm{O}_{3} / \mathrm{GCE}$, MWCNT/GCE, and $\mathrm{Bi}_{2} \mathrm{O}_{3} / \mathrm{MWCNTs} / \mathrm{GCE}$ was investigated using $\mathrm{CV}$ in a $0.1-\mathrm{M}$ phosphate buffer (pH 4.0) at a scan rate of $100 \mathrm{mV} \mathrm{s}^{-1}$ (Fig. 4). The GCE (curve a) displays a featureless cyclic voltammogram showing only background current in the absence of paracetamol. Upon addition of paracetamol, GCE (curve b) shows an irreversible behavior with an $I_{\mathrm{pa}}$ of $9.0 \mu \mathrm{A}$ at an $E_{\mathrm{pa}}$ of $551 \mathrm{mV}$. Detection on $\mathrm{B}_{2} \mathrm{O}_{3} / \mathrm{GCE}$ (curve c) is accompanied by an increase in current of $2.5 \mu \mathrm{A}$. As can be seen from curve $d$, paracetamol exhibits a pair of well-defined redox peaks on the MWCNT/GCE with $E_{\mathrm{pa}}$ at $381 \mathrm{mV}$ and $E_{\mathrm{pc}}$ at $354 \mathrm{mV}$. The increase in both anodic current and cathodic peak current in $\mathrm{CV}$ for paracetamol might be due to the electrocatalytic effect of MWCNT and increase in electroactive area. As shown by the inset B Fig. 4, the $I_{\mathrm{pa}}$ current for $\mathrm{B}_{2} \mathrm{O}_{3} / \mathrm{MWCNT} / \mathrm{GCE}$ is nearly $10.4 \mu \mathrm{A}(\approx$ 944\%), 8.2-fold $(\approx 717 \%)$ and 1.3-fold $(\approx 33.1 \%)$ higher when compared to GCE, $\mathrm{B}_{2} \mathrm{O}_{3} / \mathrm{GCE}$, and MWCNT/ GCE electrodes, respectively. The enhancement factor in $I_{\mathrm{pa}}$ and shift of the $E_{\mathrm{pa}}$ towards the lesser negative value infers that $\mathrm{B}_{2} \mathrm{O}_{3} / \mathrm{MWCNT} / \mathrm{GCE}$ is more sensitive than other electrodes in determination of paracetamol and that $\mathrm{B}_{2} \mathrm{O}_{3} / \mathrm{MWCNT} / \mathrm{GCE}$ surface has good 


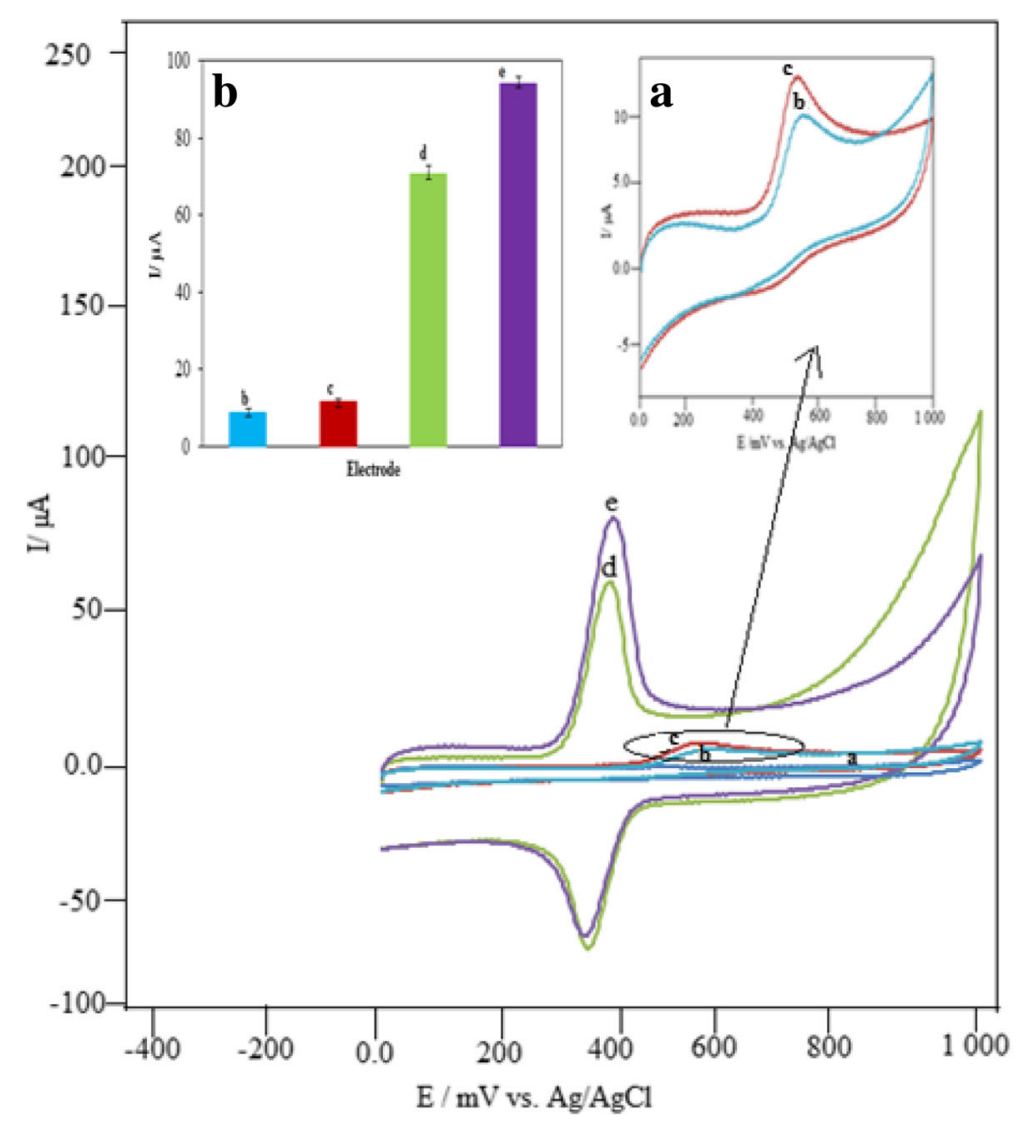

Fig. 4 CVs of GCE (curve a) in PBS (0.1 M, pH 4.0), GCE (curve b), $\mathrm{B}_{2} \mathrm{O}_{3} / \mathrm{GCE}$ (curve c), MWCNT/GCE (curve d), and $\mathrm{Bi}_{2} \mathrm{O}_{3} / \mathrm{MWCNT/GCE}$ (curve e), in $0.1 \mathrm{mM}$ paracetamol (0.1 M PBS, pH 4.0). Scan rate: $100 \mathrm{mV} \mathrm{s}^{-1}$

electrocatalytic activity towards paracetamol. Hence, $\mathrm{B}_{2} \mathrm{O}_{3} / \mathrm{MWCNT} / \mathrm{GCE}$ electrode was used in subsequent experiments as the sensing platform.

\section{Study of factors affecting the oxidation of paracetamol}

To improve the analytical characteristics of the developed sensor, a study of various factors such as the ratio of $\mathrm{Bi}_{2} \mathrm{O}_{3}$ to MWCNT, concentrations of $\mathrm{Bi}_{2} \mathrm{O}_{3} /$ MWCNT composite and volume of $\mathrm{Bi}_{2} \mathrm{O}_{3}$ /MWCNT composite injected, effect of potential cycling, $\mathrm{pH}$, and scan rate was carried out.

The influence of $\mathrm{B}_{2} \mathrm{O}_{3}$ to MWCNT amount on sensor fabrication was investigated (Fig. 5a). The current responses of the $\mathrm{B}_{2} \mathrm{O}_{3} / \mathrm{MWCNT} / \mathrm{GCE}$ sensor loading variable amount of $\mathrm{B}_{2} \mathrm{O}_{3}$ to MWCNT to oxidation of $0.1 \mathrm{mM}$ paracetamol using CVs in $0.1 \mathrm{M}$ PBS (pH 4.0) were investigated.

It is observed that the best results were obtained at a concentration ratio of $1: 3\left(\mathrm{~B}_{2} \mathrm{O}_{3}\right.$ to MWCNT). Furthermore, a total concentration of $1 \mathrm{mg} \mathrm{mL}^{-1}$ was deduced as one giving high $I_{\mathrm{pa}}$ for paracetamol (Fig. 5b). The volumes of $\mathrm{B}_{2} \mathrm{O}_{3}$ /MWCNT composite solution applied at the respective optimized total concentration on GCE electrode for studying the electrochemical behavior of paracetamol were investigated (Fig. 5b, inset). When the volume of $\mathrm{B}_{2} \mathrm{O}_{3}$ /MWCNT composite solution was increased from 1 to $5 \mu \mathrm{L}, I_{\mathrm{pa}}$ also increased due to the increased amount of composite causing effective surface area and aggregation effect to increase gradually, allowing an increase in the concentration of paracetamol on the surface of electrode. On the other hand, when the volume of $\mathrm{B}_{2} \mathrm{O}_{3} / \mathrm{MWCNT}$ composite solution was increased from 6 to $11 \mu \mathrm{L}, I_{\mathrm{pa}}$ decreased. The decrease might be explained in terms of thickness of the $\mathrm{B}_{2} \mathrm{O}_{3} / \mathrm{MWCNT}$ which had increased the diffusion distance of paracetamol hindering mass transfer and electron transfer. Consequently, $5 \mu \mathrm{L}$ of $\mathrm{B}_{2} \mathrm{O}_{3} /$ MWCNT composite solution was used in further studies for paracetamol detection.

The effect of potential cycling on $\mathrm{B}_{2} \mathrm{O}_{3} / \mathrm{MWCNT} /$ GCE was evaluated using CV by subjecting the electrode to 30 continuous potential cycles (Fig. 6) in 0.1 $\mathrm{mM}$ paracetamol. The 1st cycle had an $I_{\mathrm{pa}}$ of $42.9 \mu \mathrm{A}$ and the 30th cycle an $I_{\mathrm{pa}}$ of $39.2 \mu \mathrm{A}$ showing a decrease 

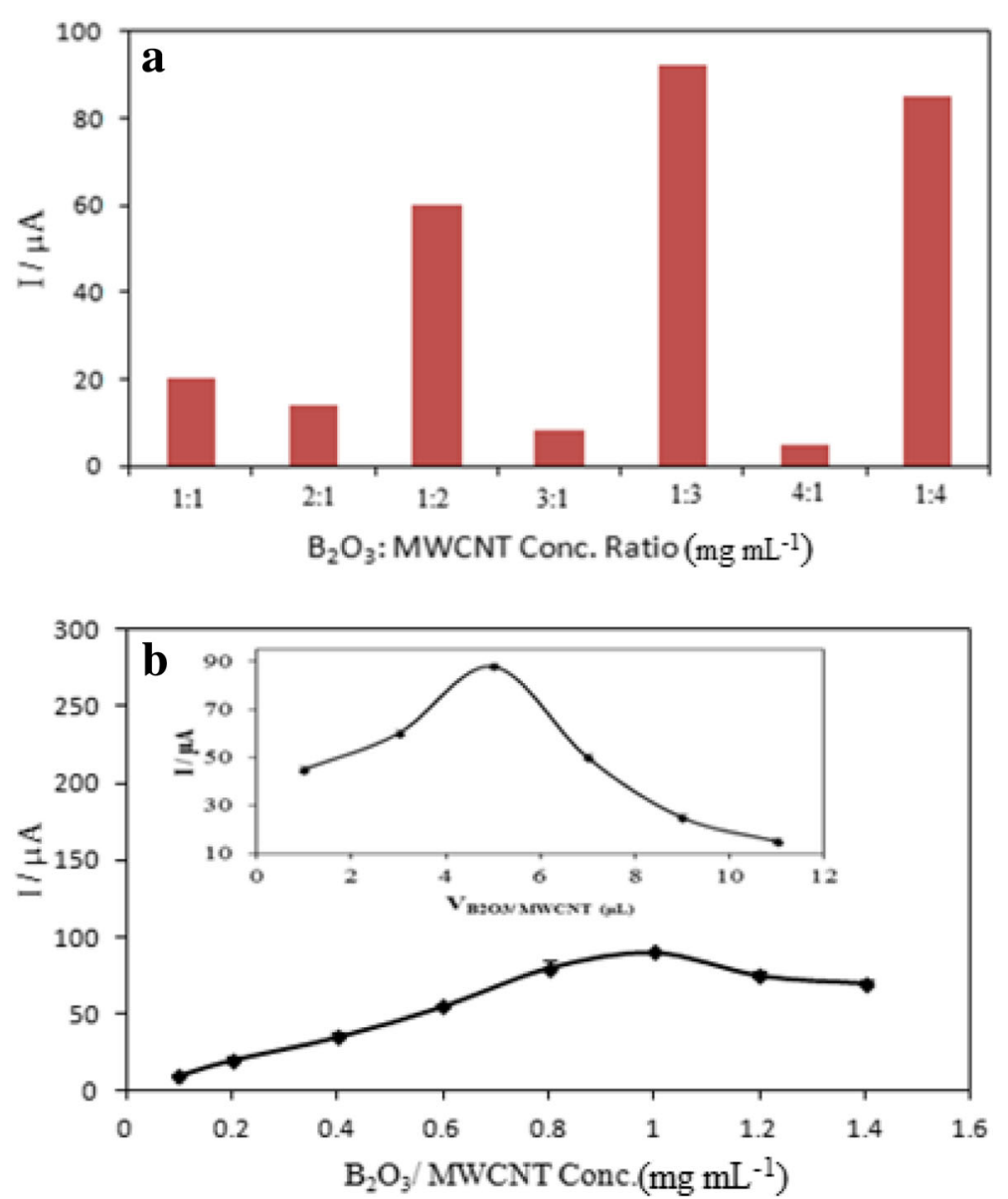

Fig. 5 Current responses of the $B_{2} \mathrm{O}_{3} / M W C N T / G C E$ sensor from a loading variable ratios of $B_{2} \mathrm{O}_{3}$ to MWCNT. $\mathbf{b}$ Different concentrations of $B_{2} \mathrm{O}_{3} /$

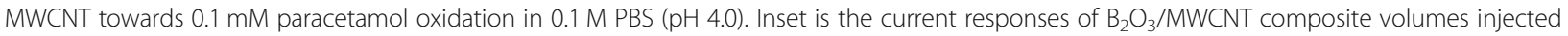
on the GCE; error bar $= \pm$ S.D. and $n=3$

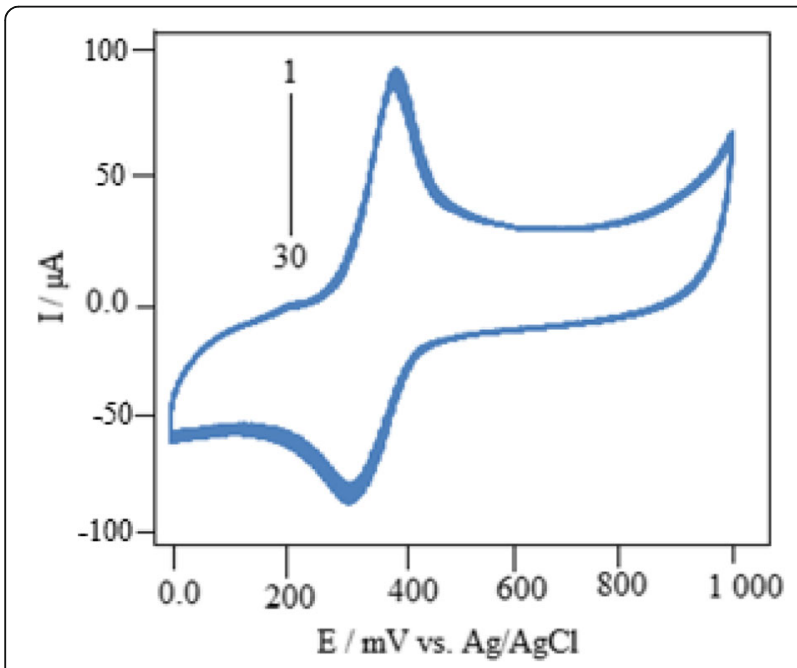

Fig. 6 Multiple CVs for $0.1 \mathrm{mM}$ paracetamol in $0.1 \mathrm{M} \mathrm{PBS}(\mathrm{pH} 4.0)$ at $\mathrm{B}_{2} \mathrm{O}_{3} /$ MWCNT/GCE. Scan rate $100 \mathrm{mV} \mathrm{s}^{-1}$ of $3.7 \mu \mathrm{A}(\approx 8.62 \%)$. The oxidation peak of paracetamol remained high during continuous potential cycling showing that $\mathrm{B}_{2} \mathrm{O}_{3} / \mathrm{MWCNT} / \mathrm{GCE}$ had good stability. Furthermore, the realization of steady condition in solid state cyclic voltammogram and that the reaction is in an equilibrium condition might be used to explain the stability (Zidan et al. 2014). Consequently, in all the studies, the oxidation peak current for paracetamol measurements was recorded in the first anodic scan in order to acquire higher sensitivity and good accuracy.

The effect of solution $\mathrm{pH}$ on the electrochemical response of the $\mathrm{Bi}_{2} \mathrm{O}_{3} / \mathrm{MWNT} / \mathrm{GCE}$ sensor towards paracetamol was investigated using $\mathrm{CV}$ in the $\mathrm{pH}$ range from 2.0 to 9.0. As shown in Fig. 7, it can be seen that paracetamol determination depended on solution $\mathrm{pH}$. Furthermore, both anodic and cathodic peak potentials were shifted to less positive side with increase in $\mathrm{pH}$ values. Similar trends have been reported (Devaraj et al. 2013; Gowda et al. 2015; Zidan et 


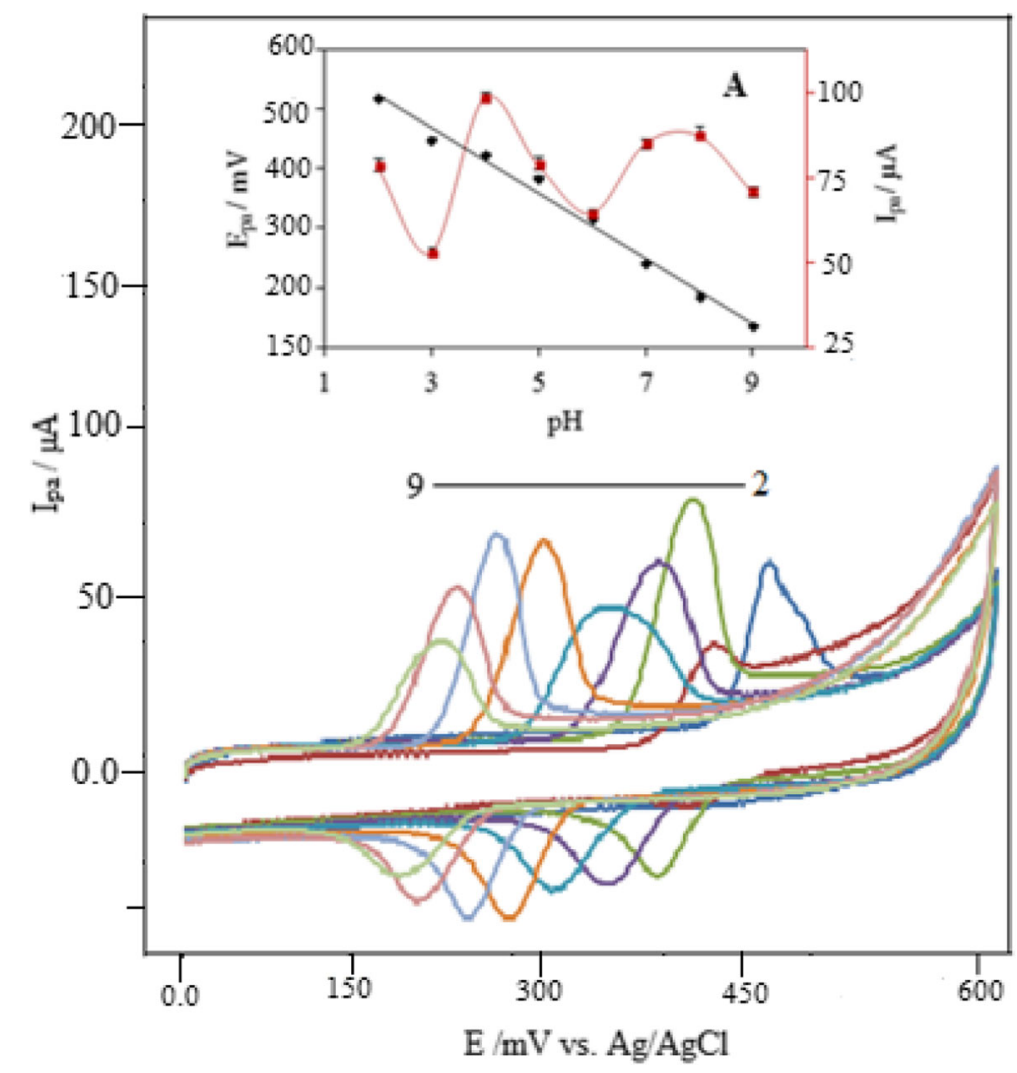

Fig. $7 \mathrm{CVs}$ of $\mathrm{Bi}_{2} \mathrm{O}_{3} /$ MWNT/GCE in $0.1 \mathrm{mM}$ paracetamol at different $\mathrm{pH}$ values (0.1 M PBS). Scan rate $100 \mathrm{mV} \mathrm{s}^{-1}$. Error bar $= \pm$ S.D. and $n=3$

al. 2011a, 2011b). The anodic peak potential of paracetamol shifted from 720 to $313 \mathrm{mV}$ with an increase in the $\mathrm{pH}$ 2.0-9.0. The linear regression equation is $E_{\mathrm{pa}}=-54.04 \quad( \pm 0.021) \quad \mathrm{pH}+835.82 \pm 0.010 \quad\left(R^{2}=\right.$ $0.9885, n=8)$ at $95 \%$ confidence interval and degrees of freedom $(n-2)$ (Miller and Miller 2010). The regression equation with a slope of $-54.04 \mathrm{mV}$ per $\mathrm{pH}$ nearly obeyed the Nernst equation for two electrons and two protons in the transfer reaction (Liu et al. 2014). The anodic oxidation peak currents decreased and increased with an increase in $\mathrm{pH}$ from 2 and the maximum was reached at 4.0 (Fig. 7 , inset), and for further studies, $\mathrm{pH} 4.0$ was selected for paracetamol determination.

The effect of scan rate on oxidation of paracetamol at $\mathrm{B}_{2} \mathrm{O}_{3}$ /MWCNT/GCE was investigated in an effort to understand the nature of the electrocatalytic process. As shown in Fig. 8, a positive shift in peak potential was observed with increase in scan rate. The anodic peak current $\left(I_{\mathrm{pa}}\right)$ and cathodic peak current $\left(I_{\mathrm{pc}}\right)$ were observed to increase linearly with scan rate in the range of $10-300 \mathrm{mV} \mathrm{s}^{-1}$ (Fig. 8, inset) due to heterogeneous kinetics (Zidan et al. 2011a, 2011b). The linear regression equations at $95 \%$ confidence interval and degrees of freedom $(n-2)$ (Miller and Miller
2010) can be expressed as follows: $I_{\mathrm{pa}}(\mu \mathrm{A})=0.28( \pm$ $0.012) v\left(\mathrm{mV} \mathrm{s}^{-1}\right)+9.17 \pm(0.12) ; R^{2}=0.9912(n=10)$; $I_{\mathrm{pc}}(\mu \mathrm{A})=-0.19( \pm 0.029) v\left(\mathrm{mV} \mathrm{s}^{-1}\right)-5.40 \pm(0.01) ; R^{2}$ $=0.9913(n=10)$. The observed results indicated that paracetamol undergoes an adsorption-controlled reaction (Bouabi et al. 2016; Kang et al. 2010; Fan et al. 2011; Liu et al. 2014; Fernandez et al. 2015; Kuskur et al. 2015; Bard and Faulkner 2001). For purely an adsorption process, the slope should be greater than 0.5 and nearly equal to 1.0 when a plot of $\log I_{\mathrm{p}}$ vs. $\log$ $v$ is plotted (Gowda et al. 2015). In our study, a slope of 0.7 was obtained (see Additional file 1: Figure S1) further indicating that paracetamol molecules remain adsorbed on $\mathrm{B}_{2} \mathrm{O}_{3} / \mathrm{MWCNT} / \mathrm{GCE}$ surface. The oxidation of paracetamol has been deduced to be a quasireversible process (Fig. 8) in which change of anodic or cathodic peak separation $\left(\Delta E_{\mathrm{pa}, \mathrm{c}}\right)$ values increase continuously with an increase in scan rate from 10 to $300 \mathrm{mV} \mathrm{s}^{-1}$. Nevertheless, at scan rates $\left(>200 \mathrm{mV} \mathrm{s}^{-1}\right)$, both $\Delta E_{\mathrm{p}}$ for cathodic and anodic are larger indicating that a limitation arises due to charge transfer kinetics. For anodic process, values of peak potentials $\left(E_{\mathrm{p}}\right)$ obtained at high scan rates are proportional to the logarithm of the scan rate $(\log v)$ (see Additional file 1: Figure S2). Using Laviron's theory (Laviron 1979), the 


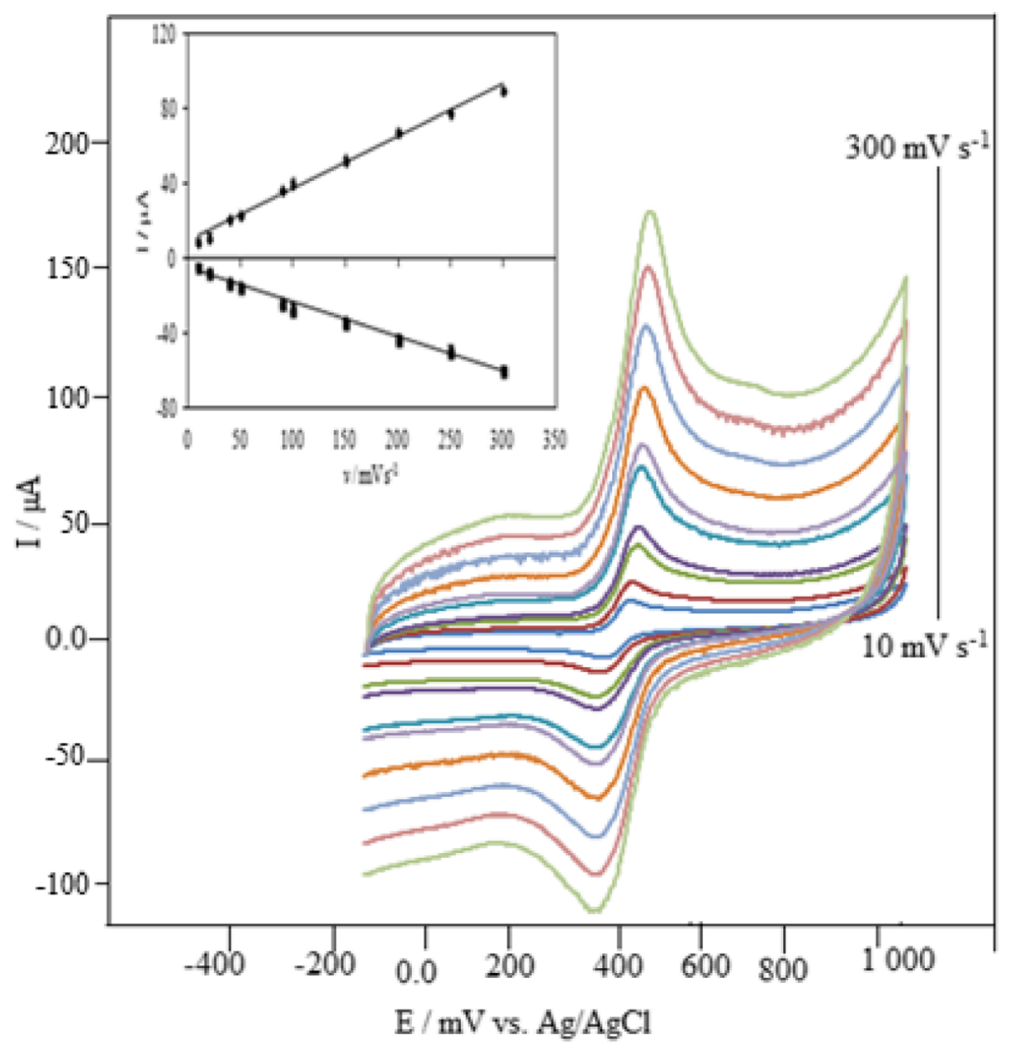

Fig. $8 \mathrm{CVs}$ acquired on $\mathrm{B}_{2} \mathrm{O}_{3} / \mathrm{MWCNT/GCE}$ with $0.1 \mathrm{mM}$ paracetamol in $0.1 \mathrm{M} \mathrm{PBS}, \mathrm{pH} 4$ at different scan rates from 10 to $300 \mathrm{mV} \mathrm{s}^{-1}$. Inset is the plot of the $I_{\text {pa }}$ of paracetamol vs. $V$

rate transfer charge coefficient $(\alpha)$ and heterogeneous electron transfer rate constant $\left(k^{0}\right)$ can also be determined using Eq. 1.1:

$$
\begin{aligned}
E_{\mathrm{P}}= & E^{0}+\frac{\mathrm{RT}}{(1-\alpha) \mathrm{nF}} \log \left(\frac{\mathrm{RTk}^{0}}{(1-\alpha) \mathrm{nF}}\right) \\
& +\left(\frac{\mathrm{RT}}{(1-\alpha) \mathrm{nF}}\right) \log v
\end{aligned}
$$

where $E^{0}$ is the formal potential, $n$ is the electron transfer number involved in the rate-determining step, and $v$ is the scan rate. $R\left(=8.314 \mathrm{~J} \mathrm{~mol}^{-1} \mathrm{~K}^{-1}\right), T(=298 \mathrm{~K})$, and $F(=$ $\left.96,480 \mathrm{C} \mathrm{mol}^{-1}\right)$ have their usual meanings. The number of electrons transferred in the reaction is two; therefore, from the slope of Eq. 1.1, the value of $\alpha$ was calculated to be 0.65 . From the intercept, by extrapolation to the ordinate axis at $v=0$, the electron transfer rate constant was calculated to be $3.14 \mathrm{~s}^{-1}$. The greater value of the electron transfer rate constant signifies high ability of the $\mathrm{B}_{2} \mathrm{O}_{3}$ / MWCNT/GCE to enhance electron transfer between paracetamol and modified electrode surface.

\section{Catalytic rate constants}

Catalytic rate constants are a measure of how facile a reaction is, hence the effectiveness of the catalysis process. The catalytic rate constant for paracetamol at $\mathrm{B}_{2} \mathrm{O}_{3} / \mathrm{MWCNT} / \mathrm{GCE}$ (Fig. 9) was determined by chronoamperometry based on favorable oxidation results from voltammetry. The rate constant can be evaluated using the Eq. 1.2

$$
\frac{I_{\text {cat }}}{I_{\text {buf }}}=\frac{\gamma^{\frac{1}{2}}\left(\pi^{1 / 2} \operatorname{erf}\left(\gamma^{\frac{1}{2}}\right)+\exp ^{-y}\right)}{\gamma^{1 / 2}}
$$

where $I_{\text {cat }}$ and $I_{\text {buf }}$ are currents on $\mathrm{B}_{2} \mathrm{O}_{3} / \mathrm{MWCNT} / \mathrm{GCE}$ in the presence and absence of paracetamol, respectively, $\gamma=k C_{o} t\left(C_{o}\right.$ is the bulk concentration of paracetamol), and erf is the error function. The error function is almost equal to 1 when $\gamma$ exceeds 2, and hence, Eq. 1.2 reduces to Eq. 1.3:

$$
\frac{I_{\text {cat }}}{I_{\text {buf }}}=\gamma^{1 / 2} \pi^{1 / 2}=\pi^{\frac{1}{2}}\left(k C_{o} t\right)^{1 / 2}
$$

where $k$ is catalytic rate constant $\left(\mathrm{cm}^{3} / \mathrm{mol} / \mathrm{s}\right)$ and $t$ is the time elapsed in seconds. The catalytic rate constant for paracetamol was calculated based on information obtained from chronoamperometry (Fig. 9). The plot of $I_{\text {cat }} / I_{\text {buf }}$ vs. $t^{1 / 2}$ for oxidation of different paracetamol concentrations gave linear plots (a). The square of the slopes against the respective concentrations (Fig. 9 (b) 


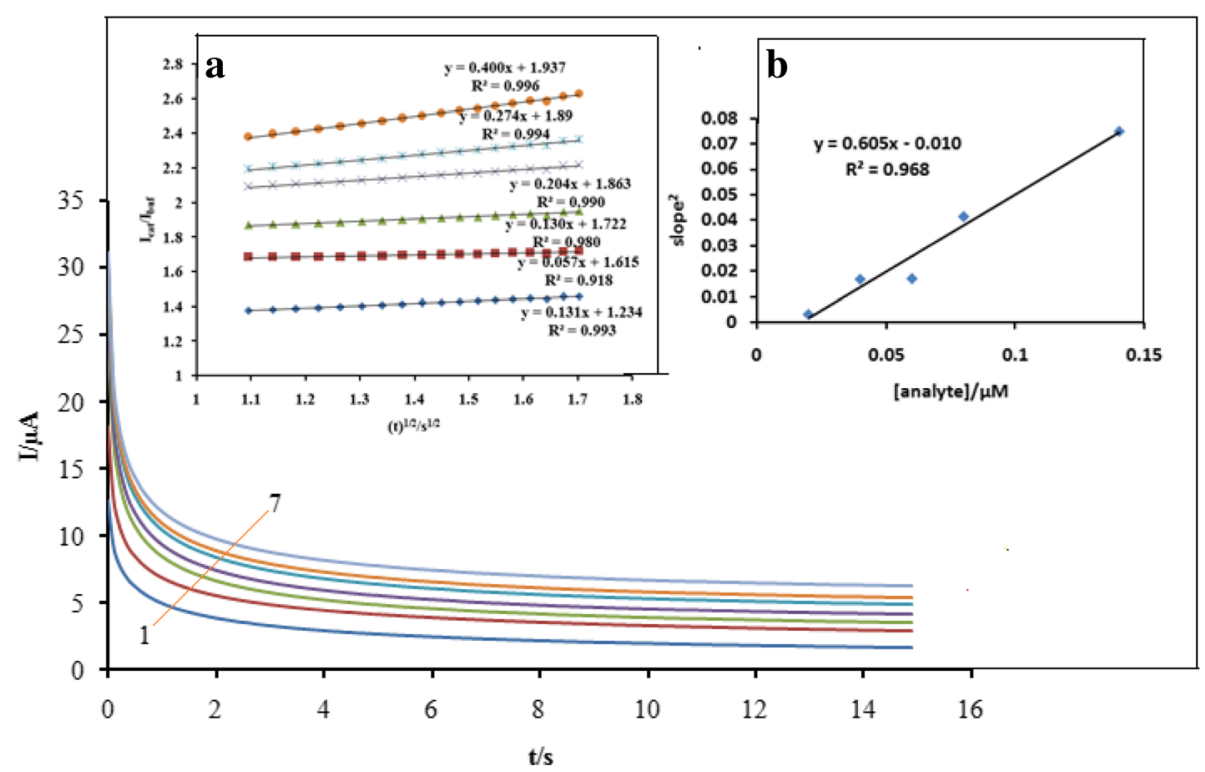

Fig. 9 Chronoamperogram for different paracetamol concentrations in 0.1 M PBS, curves 1-7: 0.02-0.14 $\mu$ M. Insets: (a) Plots of $i_{\text {cat }} / i_{\text {buffer }}$ Vs. $t^{1 / 2}$. (b) Slope $^{2}$ vs. [paracetamol]

inset) gave a linear plot whose slope is equal to $\pi \mathrm{k}$. The calculated value of catalytic constant was $1.92 \times 10^{5}$ $\mathrm{cm}^{3} / \mathrm{mol} / \mathrm{s}$ based on Eq. 1.3. The calculated value explains sharp features of catalytic $i_{\mathrm{pa}}$ of paracetamol at the surface of $\mathrm{B}_{2} \mathrm{O}_{3} / \mathrm{MWCNT} / \mathrm{GCE}$.

\section{Analytical utility of the sensor}

The relationship between current responses to paracetamol concentration was studied using SWV under optimal experimental conditions for obtaining voltammetric traces (Fig. 10). The peak current increased linearly with an increment of paracetamol concentration in the range of 0.05 to $28 \mu \mathrm{M}$ with a very good sensitivity of $1.133 \mu \mathrm{A} \mu \mathrm{M}^{-1}$. The linear regression equation at $95 \%$ confidence interval and degrees of freedom $(n-2)$ can be expressed as $I(\mu \mathrm{A})=$ $1.133( \pm 0.001) C_{\text {paracetamol }}(\mu \mathrm{M})+1.614( \pm 0.002)$ with a coefficient of determination $\left(R^{2}=0.9977, n=8\right)$.

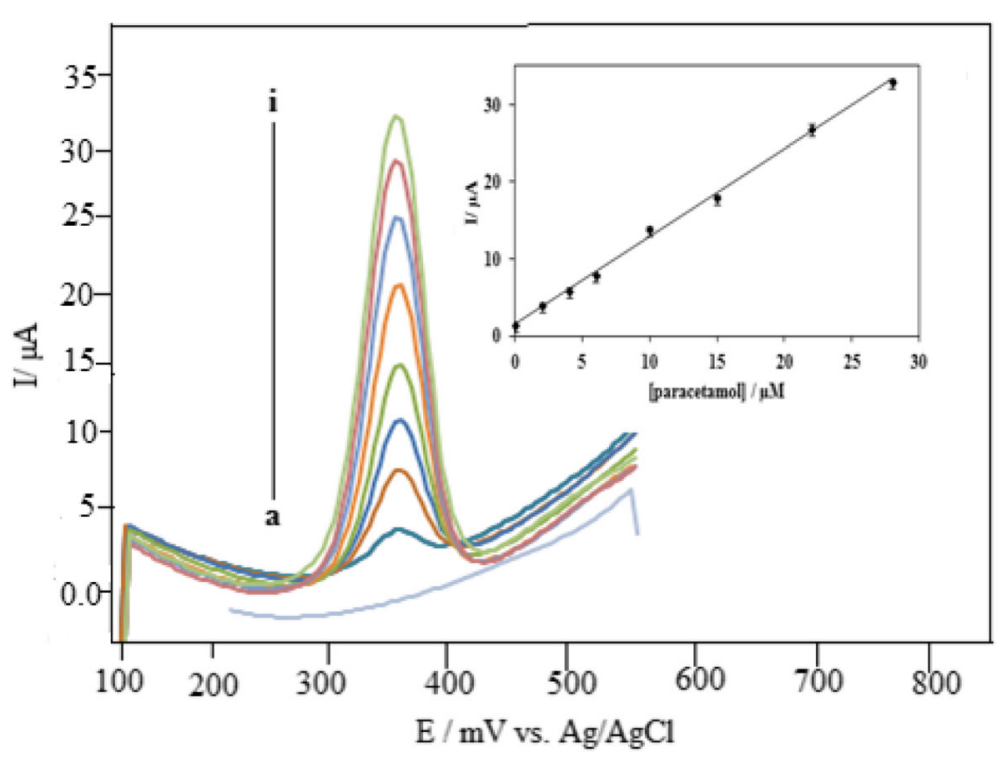

Fig. $10 \mathrm{SWVs}$ on $\mathrm{B}_{2} \mathrm{O}_{3} / \mathrm{MWCNT/GCE}$ for different paracetamol concentrations (a-i): 0.0, 0.05, 2.0, 4.0, 6.0, 10.0, 15.0, 22.0 , and $28 \mu \mathrm{M}$ in $0.1 \mathrm{M}$ PBS ( $\mathrm{pH}$ 4.0). Inset is the relationship of current responses to paracetamol concentration. Error bar $= \pm$ S.D. and $=3$ 
Table 2 Comparison of different chemically modified electrodes for the determination of paracetamol with the present fabricated sensor

\begin{tabular}{|c|c|c|c|c|c|}
\hline Modified electrode & Detection technique & $\mathrm{pH}$ of $\mathrm{PBS}$ & Linear range & Detection limit $(\mu \mathrm{M})$ & Reference \\
\hline PANI-MWCNT & SW & 5.5 & $1-100 \mathrm{M}$ & $2.5 \times 10^{-7} \mathrm{M}$ & Li and Jing 2007 \\
\hline Graphene & CV & 4.2 & $5 \times 10^{-8}$ to $1 \times 10^{-6} \mathrm{M}$ & $4.9 \times 10^{-8} \mathrm{M}$ & Zidan et al. 2014 \\
\hline Single-walled carbon nanotube/nickel & CV & 8 & $0.05-0.50 \mathrm{mM}$ & $1.17 \times 10^{-7} \mathrm{M}$ & Ngai et al. 2015 \\
\hline Cuprous oxide nanoparticles-graphene & SW & 7.0 & $0.02-1.3 \mu \mathrm{M}$ & $0.0067 \mu \mathrm{M}$ & Yang et al. 2015 \\
\hline MWCNT-CTAB & DPV & 7.4 & $0.4-4.0 \mu \mathrm{M}$ & $0.00482 \mu \mathrm{M}$ & Gowda et al. 2015 \\
\hline Chitosan & sWV & 7.0 & $1.0 \times 10^{-3}$ to $4.0 \times 10^{-4} \mathrm{M}$ & $5.08 \times 10^{-7} \mathrm{~mol} \mathrm{~L}^{-1}$ & Bouabi et al. 2016 \\
\hline AuNPs-DNS/MWCNT & DPV & 7.0 & $0.8-400 \mu \mathrm{M}$ & $0.05 \mu \mathrm{M}$ & Liu et al. 2014 \\
\hline Bismuth oxide nanoparticles & CV & 4.5 & $5.0 \times 10^{-7}$ to $1.5 \times 10^{-3} \mathrm{M}$ & $2.0 \times 10^{-7} \mathrm{M}$ & Zidan et al. 2011a, 2011b \\
\hline $\mathrm{C}-\mathrm{Ni} / \mathrm{GCE}$ & DPP & 3.0 & $2-230$ & $6.0 \times 10^{-7} \mu \mathrm{M}$ & Wang et al. 2007 \\
\hline $\mathrm{Bi}_{2} \mathrm{O}_{3} / \mathrm{MWCNT}$ & SW & 4.0 & $0.05-28 \mu \mathrm{M}$ & $0.0052 \mu \mathrm{M}$ & Present work \\
\hline
\end{tabular}

Additionally, a detection limit (LOD) of $0.0052 \mu \mathrm{M}$ was calculated using the formula as $3 s / b$, where $s$ is the standard deviation of the peak currents of blank $(n=20)$ and $b$ is the slope of the calibration plot. The performance of developed $\mathrm{B}_{2} \mathrm{O}_{3} / \mathrm{MWCNT} / \mathrm{GCE}$ sensor was compared with some selected previous modified electrodes reported elsewhere in terms of detection technique, linear range, $\mathrm{pH}$ of $\mathrm{PBS}$, and detection limit (Table 2). From the results, it can be concluded that the simple, cheap, easily prepared $\mathrm{B}_{2} \mathrm{O}_{3} /$ MWCNT/GCE sensor exhibits a very good analytical performance close to other novel components used.

\section{Impedimetric sensing}

EIS has mainly been used in sensor technology for electrode characterization (Bhengo et al. 2018). In this study, the EIS responses of the fabricated sensor to different concentrations of paracetamol were carried (Fig. 11). As can be seen in Fig. 11, the $R_{\text {et }}$ decreased with increasing paracetamol concentrations. The observation can be attributed to $\mathrm{B}_{2} \mathrm{O}_{3} / \mathrm{MWCNT} / \mathrm{GCE}$ offering a favorable platform for electrochemical oxidation. The electrons generated during the oxidation reaction helps in enhanced charge transfer rate leading to a decrease in $R_{\text {et }}$ value. Increasing the concentration of

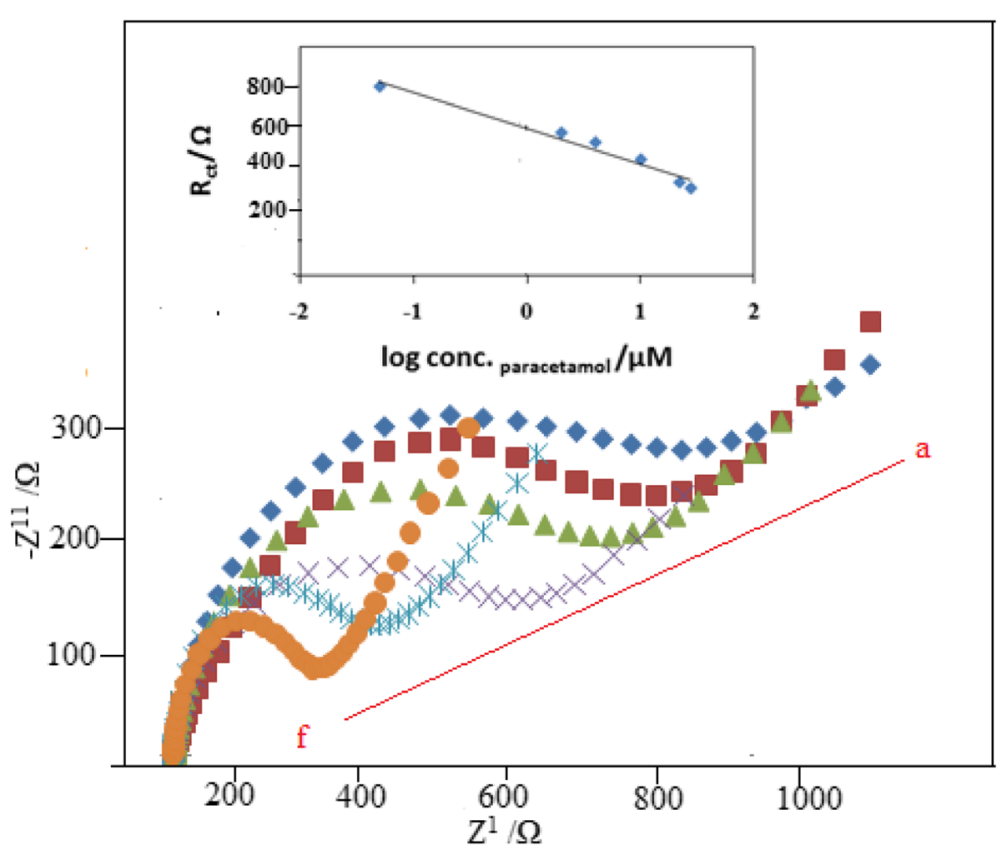

Fig. 11 EIS spectra at $\mathrm{B}_{2} \mathrm{O}_{3} / \mathrm{MWCNT} / \mathrm{GCE}$ for different paracetamol concentrations in $0.1 \mathrm{M}$ PBS (pH 4.0). Inset: variation of $R_{\mathrm{ct}}$ with $\log [$ paracetamol] $/ \mu \mathrm{M}$ 
paracetamol (Fig. 11) caused the $R_{\text {et }}$ value to decrease markedly consequently enhancing the electrode kinetics. The results provide possible use for this technique for analysis of analytes.

\section{Storage, stability, and reproducibility}

The long-term stability of $\mathrm{B}_{2} \mathrm{O}_{3} / \mathrm{MWCNT} / \mathrm{GCE}$ sensor was also investigated by storing the same electrode at room temperature and intermittently testing it in 0.1 M PBS containing $10 \mu \mathrm{M}$ paracetamol. In Additional file 1: Figure S3, the current values maintain more than $90 \%$ of the initial value after keeping for 25 days showing that it can be used for a continual operation. The reproducibility of the developed sensor was evaluated by comparing the current responses of different sensors under the same preparation conditions. The current responses of six different $\mathrm{B}_{2} \mathrm{O}_{3} /$ MWCNT/GCE (fabricated by the same approach) to paracetamol oxidation were tested independently. The current responses of six modified electrodes provide a relative standard deviation (RSD) value of $3.50 \%$ indicating a good reproducibility.

\section{Interference study}

The possible interferences for determination of paracetamol using $\mathrm{B}_{2} \mathrm{O}_{3} / \mathrm{MWCNT} / \mathrm{GCE}$ sensor were evaluated. Under the optimized conditions, the peak currents of $10 \mu \mathrm{M}$ paracetamol were individually measured using SWV after addition of 10-fold of organic molecules such as glucose, salicylic acid, and ascorbic acid and 100-fold inorganic ions such as $\mathrm{Na}^{+}, \mathrm{Ca}^{2+}, \mathrm{Cl}^{-}$, and $\mathrm{Mg}^{2+}$ and the peak current change was then checked. As seen in Additional file 1: Figure S4, no major influences on the detection of paracetamol were observed and the peak current changes were $<10 \%$.

\section{Analytical application}

The $\mathrm{B}_{2} \mathrm{O}_{3} / \mathrm{MWCNT} / \mathrm{GCE}$ sensor was used to detect paracetamol in human urine. A $1.0-\mathrm{mL}$ urine sample was added into each of the series of $10 \mathrm{~mL}$ volumetric flasks. Paracetamol standard solutions of different concentrations were added to the flask, which were made up to volume with $0.1 \mathrm{M}$ PBS. An aliquot of 5.0 $\mathrm{mL}$ of the solution was placed in a cell for determination and SWV were run. The results are shown in Table 3. As can be seen, the recoveries (94.3-98.7\%)

Table 3 Determination of paracetamol in human urine samples

\begin{tabular}{llll}
\hline Samples & Added $(\mu \mathrm{M})$ & Found $^{\mathrm{a}}(\mu \mathrm{M})$ & Recovery $(\%)$ \\
\hline 1 & 1.0 & 0.987 & $98.7 \pm 0.1$ \\
2 & 6.0 & 5.86 & $97.7 \pm 0.5$ \\
3 & 12.0 & 11.32 & $94.3 \pm 0.8$ \\
\hline
\end{tabular}

${ }^{\mathrm{a}}$ Average of five determinations for the determination of paracetamol added to urine samples were obtained.

\section{Conclusion}

In the present study, a good electrocatalytic response for the oxidation of paracetamol was shown by $\mathrm{Bi}_{2} \mathrm{O}_{3} /$ MWCNT/GCE with $I_{\text {pa }}$ of nearly 8.2 -fold $(\approx$ $717 \%)$ higher when equated to GCE. The scan rate studies indicated that the paracetamol undergoes a surface-confined process on the modified electrode. Calibration plot reveals linearity from the range 0.02 to $28 \mu \mathrm{M}$ with a good sensitivity of $1.067 \mu \mathrm{A} \mu \mathrm{M}^{-1}$. The detection limit was estimated to be $0.0052 \mu \mathrm{M}$. Based on interference studies, some organic and inorganic substances studied do not affect the response of paracetamol at the $\mathrm{B}_{2} \mathrm{O}_{3} / \mathrm{MWCNT} / \mathrm{GCE}$ surface.

\section{Additional file}

Additional file 1: Figure S1. Plot of $\log I_{\mathrm{pa}}$ vs. $\log v$. Figure S2. Plot of $\log E$ vs. $\log v$. Figure S3. Effect of storage time of $\mathrm{B}_{2} \mathrm{O}_{3} /$ MWCNT/GCE on the current response to $10 \mathrm{MM}$ paracetamol. Figure S4. Oxidation signal change of $10 \mu \mathrm{M}$ paracetamol in the presence of interferences. (DOCX 22 $\mathrm{kb})$

\section{Abbreviations \\ AuNPs-DNS: Functionalized dopamine nanospheres; Bi: Bismuth; $\mathrm{Bi}_{2} \mathrm{O}_{3}$ : Bismuth (III) oxide; C: Carbon; C-Ni: Carbon-coated nickel; CTAB: Cetyltrimethyl ammonium bromide; CV: Cyclic voltammetry; DMF: N,N-dimethylformamide; EIS: Electrochemical impedance spectroscopy; $E_{\text {pa: }}$ Anodic peak potential; FT- IR: Fourier transform infrared spectroscopy; GCE: Glassy carbon electrode; $I_{\text {pa: }}$ Anodic peak current; $I_{\text {pc: }}$ Cathodic peak current; $\mathrm{K}_{3} \mathrm{Fe}(\mathrm{CN})_{6}$ : Potassium ferricyanide; $\left.\mathrm{K}_{4} \mathrm{Fe}(\mathrm{CN})_{6}\right)$ : Potassium ferrocyanide; MWCNT: Multiwalled carbon nanotube; PANI: Polyaniline; PBS: Phosphate buffers solutions; SEM- EDS: Scanning electron microscopy-energy dispersive $X$-ray; SW: Square wave voltammetry; $\mathrm{TiO}_{2}$ : Titanium dioxide; $\Delta E_{\mathrm{pa}, \mathrm{c}}:$ Change in anodic or cathodic peak potential}

\section{Acknowledgements}

The authors would like to acknowledge the laboratory facilities from Midlands State University, Gweru, Zimbabwe.

\section{Authors' contributions}

The original idea of the work was planned and executed by MM. ATC and DA carried out the preparation and experimental work. MM helped in the interpretation of the results and in the drafting of the manuscript. All authors read and approved the final manuscript.

\section{Funding}

The authors did not receive any fund from any person or organization or society.

\section{Availability of data and materials}

The research data have been provided in the manuscript.

\section{Ethics approval and consent to participate}

Approved

Competing interests

The authors declare that they have no competing interests. 
Received: 29 December 2018 Accepted: 19 May 2019

Published online: 26 May 2019

\section{References}

Abdelaleem EA, Abdelwahab NS. Validated stability indicating RP-HPLC method for determination of paracetamol, methocarbamol and their related substances. Anal Methods. 2013;5:541-5.

Bhengo T, Moyo M, Shumba M, Okonkwo OJ. Simultaneous oxidative determination of antibacterial drugs in aqueous solutions using an electrode modified with MWCNTs decorated with $\mathrm{Fe}_{3} \mathrm{O}_{4}$ nanoparticles. New J Chem. 2018;42:5014-23.

Bouabi YEL, Farahi A, Labjar N, Hajjaji SE, Bakasse M, Mhammedi MAE. Square wave voltammetric determination of paracetamol at chitosan modified carbon paste electrode: application in natural water samples, commercial tablets and human urines. Mater Sci Eng C. 2016;58:70-7.

Bard AJ, Faulkner LR. Electrochemical methods, fundamentals and applications. 2nd ed. New York: Wiley; 2001. p. 161.

Chen X, Chen S, Huang W, Zheng J, Li Z. Facile preparation of Bi nanoparticles by novel cathodic dispersion of bulk bismuth electrodes. ElectrochimActa. 2009; 54:7370-3.

Deroco PB, Vicentini FC, Fatibello-Filho O. An electrochemical sensor for the simultaneous determination of paracetamol and codeine using a glassy carbon electrode modified with nickel oxide nanoparticles and carbon black. Electroanalysis. 2014;27:2214-20.

Devaraj M, Deivasigamani RK, Jayadevan S. Controlled growth and molecular selfassembly of Au nanoparticles to Au nanochains: application towards enhancement for the electrochemical determination of paracetamol. Anal Methods. 2013;5:3503-15.

Eda CG, Jolanta-Ewa KS, Ludvik M. Effect of post deposition annealing on the structure, composition and the mechanical and optical characteristics of niobium and tantalum oxide films. Appl Opt. 2012;51:6498-507.

Fan Y, Liu JH, Lu HT, Zhang Q. Electrochemical behavior and voltammetric determination of paracetamol on Nafion/ $/ \mathrm{TiO}_{2}$-graphene modified glassy carbon electrode. Colloids Surf B. 2011;85:289-92.

Feizbakhsh A, Aghassi A, Ehsani A, Jamaat MA, Naeemy A, Danaee I. Electrocatalytic oxidation of paracetamol on $\mathrm{Ni}$ and $\mathrm{NiCu}$ alloy modified glassy carbon electrode. J Chin Chem Soc. 2012;59:1086-93.

Fernandez C, Heger Z, Kizek R, Ramakrishnappa T, Boruń A, Faisal NH. Pharmaceutical electrochemistry: the electrochemical oxidation of paracetamol and its voltammetric sensing in biological samples based on screen printed graphene electrodes. Int J Electrochem Sci. 2015;10:7440-52.

Gowda Jl, Gunjiganvi DG, Sunagar NB, Bhat MN, Nandibewoor ST. MWCNT-CTAB modified glassy carbon electrode as a sensor for the determination of paracetamol. RSC Adv. 2015;5:49045-53.

Gupta VK, AJain AK, Maheshwari G, Lang H, Ishtaiwi Z. Copper(II)-selective potentiometric sensors based on porphyrins in PVC matrix. SensActuat B. 2006;117:99-106.

Jia L, Zhang XH, Li Q, Wang SF. Determination of acetaminophen by square wave voltammetry at a gold electrode modified by 4-amino-2mercaptopyrimidine self-assembled monolayers. J Anal Chem. 2007;62:266-9.

Kachoosangi RT, Wildgoose GG, Compton RG. Sensitive adsorptive stripping voltammetric determination of paracetamol at multiwalled carbon nanotube modified basal plane pyrolytic graphite electrode. Anal ChimActa. 2008;618:54-60.

Kang X, Wang J, Wu H, Liu J, Aksay IA, Lin Y. A graphene-based electrochemical sensor for sensitive detection of paracetamol. Talanta. 2010;81:754-9.

Kuskur CM, Kumara BES, Jayadevappa H. Electrochemical investigation of paracetamol at poly(glycine) modified carbon paste electrode: a voltametric study. J Anal Bioanal Tech. 2015;6(4):1-6.

Laviron E. General expression of the linear potential sweep voltammogram in the case of diffusionless electrochemical systems. J Electroanal Chem. 1979;101:19-28.

Li C, Zhan G, Yang Q, Lu J. Electrochemical investigation of acetaminophen with a carbon nano-tube composite film electrode. Bull Kor Chem Soc. 2006; 27(11):1854-60.

$\mathrm{Li} \mathrm{L}$, Yan B. $\mathrm{BiVO}_{4} / \mathrm{Bi}_{2} \mathrm{O}_{3}$ submicrometer sphere composite: microstructure and photocatalytic activity under visible-light irradiation. J Alloys Compd. 2009;476:624-8.

Li M, Jing LH. Electrochemical behavior of acetaminophen and its detection on the PANI-MWCNTs composite modified electrode. ElectrochimActa. 2007;52:3250-7.

Liu X, Zhang XY, Wang LL, Wang YY. A sensitive electrochemical sensor for paracetamol based on a glassy carbon electrode modified with multiwalled carbon nanotubes and dopamine nanospheres functionalized with gold nanoparticles. MicrochimActa. 2014;181:1439-46.
Lou HG, Yuan H, Ruan ZR, B Jiang B. Simultaneous determination of paracetamol, pseudoephedrine, dextrophan and chlorpheniramine in human plasma by liquid chromatography-tandem mass spectrometry. J Chromatogr B Anal Technol Biomed Life Sci. 2010:878:682-8.

Mafuwe PT, Moyo M, Mugadza T, Shumba M, Nyoni S. Cobalt oxide nanoparticles anchored polyaniline appended cobalt tetracarboxy phthalocyanine, modified glassy carbon electrode for facile electrocatalysis of amitrole. J Solid State Electrochem. 2019; 23:285-94.

Miller JN, Miller JC. Statistics and chemometrics for analytical chemistry. sixth ed. England: Prentice Hall; 2010.

Moyo M, Lehutso RF, Okonkwo OJ. Improved electro-oxidation of triclosan at nano-zinc oxide-multiwalled carbon nanotube modified glassy carbon electrode. SensActuat B. 2015;209:898-905

Ngai KS, Tan WT, Zainal Z, Zawawi RM, Juan JC. Electrocatalytic study of paracetamol at a single-walled carbon nanotube/nickel nanocomposite modified glassy carbon electrode. Adv Mater Sci Eng. 2015;2015:1-8.

Ovsienko V, Len TA, Matzui LY, Prylutskyy YI, Ritter U, Scharff P, Le Normand F, Eklund P. Transport properties of carbon nanotube-metal nanocomposites. Mol CrystLiqCryst. 2007:468:289-97.

Periasamy AP, Yang S, Chen SM. Preparation and characterization of bismuth oxide nanoparticles-multiwalled carbon nanotube composite for the development of horseradish peroxidase based $\mathrm{H}_{2} \mathrm{O}_{2}$ biosensor. Talanta. 2011;87:15-23.

Rowden AK, Norvell J, Eldridge DL, Kirk MA. Acetaminophen poisoning. Clin Lab Med. 2006;26:49-65.

Sullivan JE, Farrar HC, Fever and antipyretic use in children. Pediatrics. 2011;127: 580-7.

Sultan MA, Maher HM, Alzoman NZ, Alshehri MM, Rizk MS, Elshahed MS, Olah LV. Capillary electrophoretic determination of antimigraine formulations containing caffeine, ergotamine, paracetamol and domperidone or metoclopramide. J Chromatogr Sci. 2013:51:502-10.

Wang SF, Xie F, Hu RF. Carbon-coated nickel magnetic nanoparticles modified electrodes as a sensor for determination of acetaminophen. Sens Actuators B. 2007;123:495-500.

Xu H, Xiao J, Liu B, Griveau S, Bedioui F. Enhanced electrochemical sensing of thiols based on cobalt phthalocyanine immobilized on nitrogen doped graphene. Biosens Bioelectron. 2015;66:438-44.

Yang H, Liu B, Ding Y, Li L, Ouyang X. Fabrication of cuprous oxide nanoparticlesgraphene nanocomposite for determination of acetaminophen. J Electroanal Chem. 2015;757:88-93.

Yin H, Meng X, Xu Z, Chen L, Ai S. Electrochemical behavior of phenacetin on CdSe microspheres modified glassy carbon electrode and its simultaneous determination with paracetamol and 4-aminophenol. Anal Methods. 2012;4:1445-51.

Zidan M, RZawawi RM, Erhayem M, Salhin A. Electrochemical detection of paracetamol using graphene oxide-modified glassy carbon electrode. Int J Electrochem Sci. 2014;9: 7605-13.

Zidan M, Tee TW, Abdullah AH, Zainal Z, Kheng GJ. Electrochemical oxidation of paracetamol mediated by $\mathrm{MgB}_{2}$ microparticles modified glassy carbon electrode. E-J Chem. 2011a;8(2):553-60.

Zidan M, Tee TW, Abdullah AH, Zainal Z, Kheng GJ. Electrochemical oxidation of paracetamol mediated by nanoparticles bismuth oxide modified glassy carbon electrode. Int J Electrochem Sci. 2011b;6:279-88.

\section{Publisher's Note}

Springer Nature remains neutral with regard to jurisdictional claims in published maps and institutional affiliations. 